\title{
Levantine Intermediate Water characteristics: an astounding general misunderstanding! (addendum)
}

\author{
Claude Millot \\ Les Katikias, 83150 Bandol, France. E-mail: ailesetiles@gmail.com
}

\begin{abstract}
Summary: Discussions following the publication of "Levantine Intermediate Water characteristics: an astounding general misunderstanding!" (Millot 2013a) confirmed that this warm salty (similar results with cool fresh) intermediate water was generally thought to be characterized, even after significant mixing, by a homogeneous core (i.e. a do/dz minimum) while we think it could be characterized by a do/dz maximum. Additional computations specify our feelings and suggest that only such a hypothetical $\mathrm{d} \sigma / \mathrm{dz}$ maximum can provide information about the characteristics of these intermediate waters, in this case only the local immersion of the core, since the associated $\sigma$ depends essentially on the $\sigma$ values of all the surrounding waters encountered upstream, while the $\theta$ and $S$ maxima evolve continuously. Because we are convinced that such studies have a global importance and deserve much more interest than they have received up to now, we hope that these additional computations and data analyses will motivate really theoretical studies that could be easily checked with a consequent data set available all over the Mediterranean Sea in particular.
\end{abstract}

Keywords: Mediterranean Sea; water mass; temperature; salinity; maximum; extremum.

Las características de LIW: un malentendido asombroso! (adenda)

Resumen: Discusiones a partir de la publicación de "Levantine Intermediate Water characteristics: an astounding general misunderstanding!" (Millot 2013a) confirmaron que esta masa de agua intermedia caliente y salada (igualmente válido para un agua fría y dulce) se había considerado siempre caracterizada, incluso tras ser significativamente mezclada, por un núcleo homogéneo (o sea un mínimo de dø/dz), mientras que nosotros pensamos que podría caracterizarse por un máximo de do/dz. Cálculos adicionales especifican esta idea y sugieren que únicamente este hipotético máximo de do/dz puede proporcionar información sobre las características de dicha masa de agua, en este caso sólo la profundidad local del núcleo, mientras que la $\sigma$ asociada depende esencialmente de los valores de $\sigma$ de todas las aguas arriba circundantes, mientras que los máximos de $\theta$ y S evolucionan continuamente. Dado que estamos convencidos que estos estudios tienen una importancia global y merecen mucho más interés que el recibido hasta ahora, esperamos que estos cálculos adicionales y análisis de datos motivarán estudios teóricos que podrían ser fácilmente verificados con conjuntos de datos disponibles en particular en todo el Mediterráneo.

Palabras clave: mar Mediterráneo; masa de agua; temperatura; salinidad; máximo; extremo.

Citation/Como citar este artículo: Millot C. 2014. Levantine Intermediate Water characteristics: an astounding general misunderstanding! (addendum). Sci. Mar. 78(2): 165-171. doi: http://dx.doi.org/10.3989/scimar.04045.30H

Editor: J. Font.

Received: January 30, 2014. Accepted: February 28, 2014. Published: June 4, 2014.

Copyright: (c) 2014 CSIC. This is an open-access article distributed under the Creative Commons Attribution-Non Commercial Lisence (by-nc) Spain 3.0.

\section{ADDITIONAL COMPUTATIONS}

As emphasized in Millot (2013a), we do not pretend to perform a sophisticated analysis of the mixing process encountered by a layer of intermediate water (IW) while spreading and circulating from its zone of formation. We just want to emphasize the importance of the problem and explain some obvious features that are, astoundingly, generally misunderstood. Our aim is to motivate really theoretical studies and exhaustive data analyses. As this paper is just an addendum, we do not provide information already provided in Millot (2013a).

First, we propose with Figure 1 more information about the case dealt with in Figure 4 in Millot (2013a). While information about the density $(\sigma)$ profile and values inferred from an individual cast (as in Fig. 1d) do not provide usable information, it appears that the do/dz maxima (Fig. 1e) remain located close to the initial immersion of the IW core while the $\theta$ and $\mathrm{S}$ 

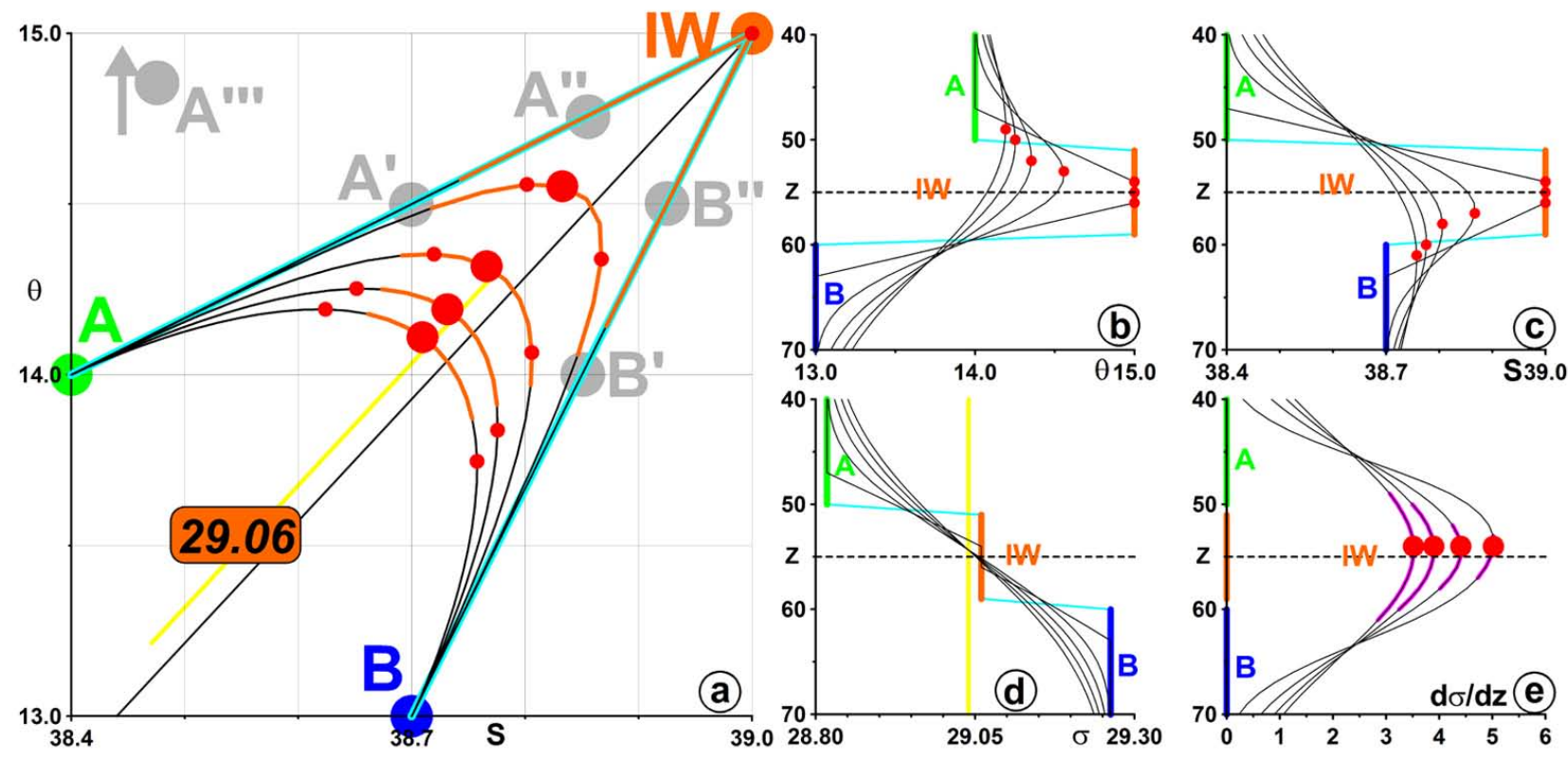

Fig. 1 - a) water mass names are as in Millot (2013a). The yellow isopycnal is $(\sigma(\mathrm{A})+\sigma(\mathrm{B})) / 2$. Large red dots correspond to the do/dz maxima at the various time steps (not specified since obvious). Other information is as in Millot (2013a). b) and c) as in Millot (2013a). d) density profiles. Note the difference between $\sigma(\mathrm{IW})\left(29.06 \mathrm{~kg} \mathrm{~m}^{-3}\right)$ and $(\sigma(\mathrm{A})+\sigma(\mathrm{B})) / 2\left(29.04 \mathrm{~kg} \mathrm{~m}^{-3}\right.$, i.e. $\left.(28.82+29.26) / 2\right)$ in yellow, the latter seemingly corresponding to the inflexion points of the $\sigma$ profiles at depths shallower than that of the initial IW core. e) density gradient $(\mathrm{d} \sigma / \mathrm{dz})$ profiles are relatively symmetric with respect to the initial immersion of the IW core. Pink portions of the curves mark the distance between the $\theta$ and $\mathrm{S}$ maxima.

maxima continuously move away. Note that, due to the values we chose, $\sigma(\mathrm{IW})$ is not very different from $(\sigma(\mathrm{A})+\sigma(\mathrm{B})) / 2$; however, the former is larger than the latter and the do/dz maxima are at slightly shallower depths.

Second, we propose with Figure 2 more information about one of the cases dealt with in Figure 5 in Millot (2013a) (the A'-B one in Fig. 5b), since all other cases can be easily inferred from that one. Information about the $\sigma$ profile and values (Fig. 2d) still do not provide usable information, while the immersion of the do/dz maxima (Fig. 2e) apparently still tends towards the initial immersion of the IW core. Note that, due to the values we chose, $\sigma$ (IW) is now markedly different from $\left(\sigma\left(\mathrm{A}^{\prime}\right)+\sigma(\mathrm{B})\right) / 2$; the former is lower than the latter and the $\mathrm{d} \sigma / \mathrm{dz}$ maxima are at markedly larger depths.
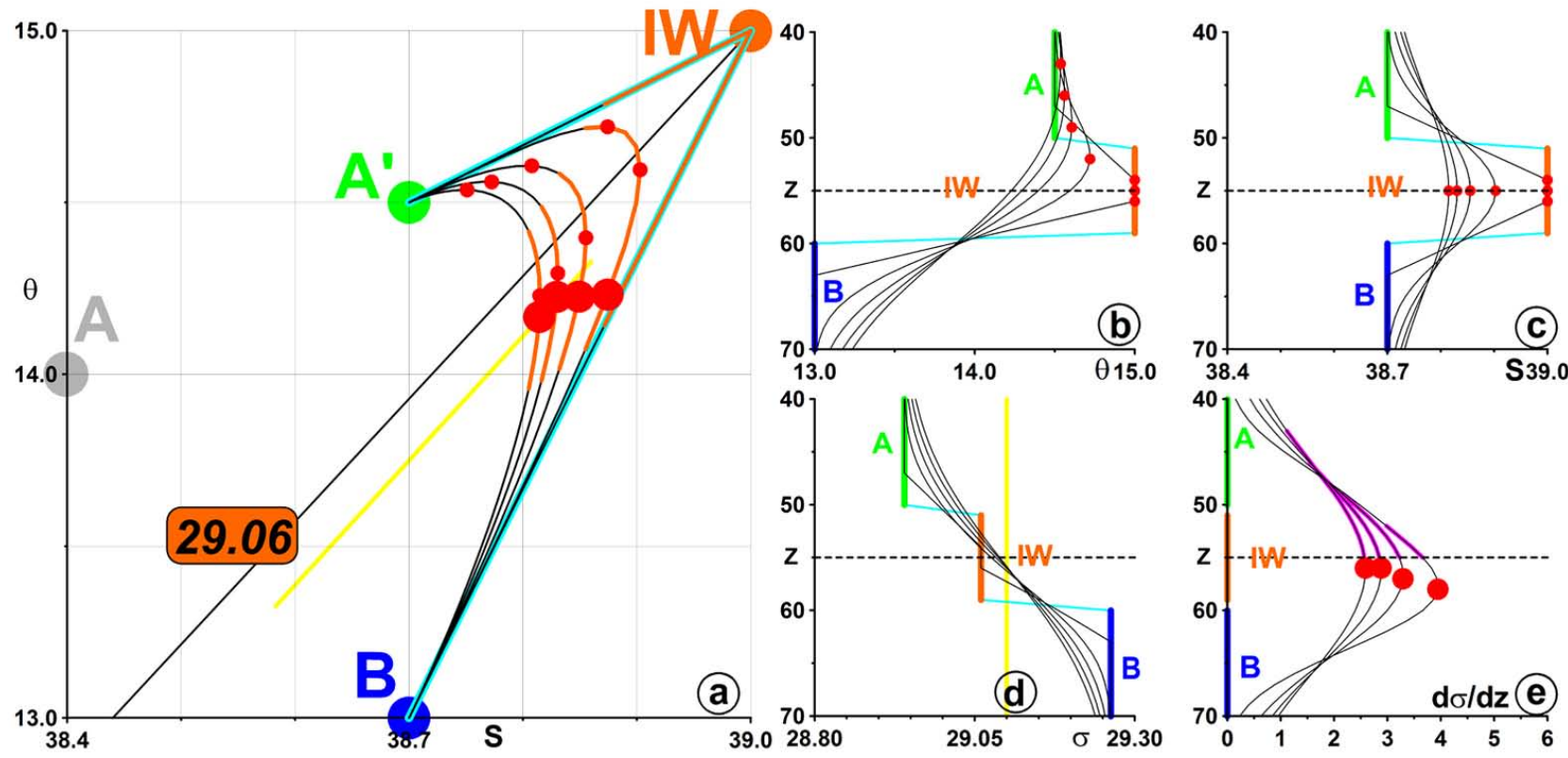

Fig. 2. - a) as in Figure 1 for the case A'-B. b) and c) as in Figure 1. Note that the S maximum remains at the initial immersion of the IW

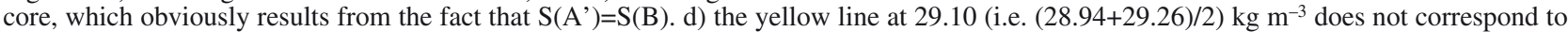
the inflexion points of the $\sigma$ profiles that are at depths deeper than that of the initial IW core. e) do/dz profiles tend to become more and more symmetric with respect to the initial immersion of the IW core. 
Comparison of Figures 1 and 2 suggests that: i) if $\sigma(\mathrm{IW})$ is larger (resp. lower) than $\left(\sigma\left(\mathrm{A}_{\text {or }} \mathrm{A}^{\prime}\right)+\sigma(\mathrm{B})\right) / 2$, the $d \sigma / d z$ maximum is above (resp. below) the initial immersion of the IW core, the greater the difference in density, the greater the difference in depth; and ii) the immersion of the do/dz maxima tends towards the initial immersion of the IW core, seemingly never reaching it.

To check the importance of the IW thickness in the effectiveness of the do/dz maxima to tend towards the initial immersion of the IW core or towards another location, we consider with Figure 3 the case of a thin intermediate layer or a pellicle (IP): instead of considering an IW spreading over 9 depth units (see Millot 2013a), we consider the A-B case (both with 50 depth units) for an IP of only 1 depth unit: this case clearly demonstrates that a sharp do/dz maximum is rapidly created and rapidly converges towards the initial immersion of the IW core. What can be concluded from the analysis of this elementary representation of the mixing (averaging $\theta$ and $\mathrm{S}$ over the vertical) of a layer of warm and salty (as well as cool fresh, see Millot (2013a)) intermediate water is that, as soon as the mixing with the layers above and below has reached the IW core, i.e. as soon as the $\theta$-S diagram associated with this IW is no longer sharp and displays some smoothness, no information about the initial IW characteristics can be obtained from any analysis of the $\theta, S$ and $\sigma$ profiles, as inferred from CTD casts for instance. Only the immersion of the do/dz maximum associated with that IW can allow the local immersion of the IW core to be specified; the associated $\sigma$ depends essentially on those of all the surrounding waters encountered upstream while the $\theta$ and $\mathrm{S}$ maxima evolve continuously.

\section{ADDITIONAL DATA ANALYSIS}

Obviously, overall do/dz maxima in the Mediterranean Sea are associated with the interface between the incoming Atlantic Waters (AWs) and the Mediterranean Waters (MWs) formed in the sea. But, though this overall maximum has been widely studied, in particular in the Strait of Gibraltar at depths of, in general, 100$200 \mathrm{~m}$, we are not aware of any study having focused on what could be named "intermediate do/dz maxima" within the MWs. Moreover, since it is a general belief that the cores of intermediate waters such as Levantine Intermediate Water (LIW) are relatively homogeneous, hence associated with $\mathrm{d} \sigma / \mathrm{dz}$ minima, we are aware that the debate we open will not be easy. Therefore, our aim, when focusing on just a few profiles among the thousands available in the data bases, is just to propose an analysis as objective as possible and promising enough to motivate dedicated and exhaustive data analyses. We focus on data from the campaigns \#1 and \#2 of the 1986 Gibraltar Experiment GIBEX conducted in March-April and September-October, respectively, which are extremely valuable data sets that have recently been re-analysed by Millot $(2009,2013 b)$ and named GIB1 and GIB2.

$\theta$ and $\mathrm{S}$ sections as well as the locations of the $\theta, \mathrm{S}$ and $\mathrm{d} \sigma / \mathrm{dz}$ maxima associated with LIW (we no longer specify hereafter that they are intermediate maxima) in Figure 3 of Millot (2013a) were inferred from raw data files that, as shown by the black $\theta$ and $S$ profiles in Figures 4 (GIB1) and 5 (GIB2), are relatively noisy. In order to perform an analysis that is as objective as possible, we first computed $\sigma$ profiles from smoothed $\theta$ and $\mathrm{S}$ ones (running a rectangular average over 19
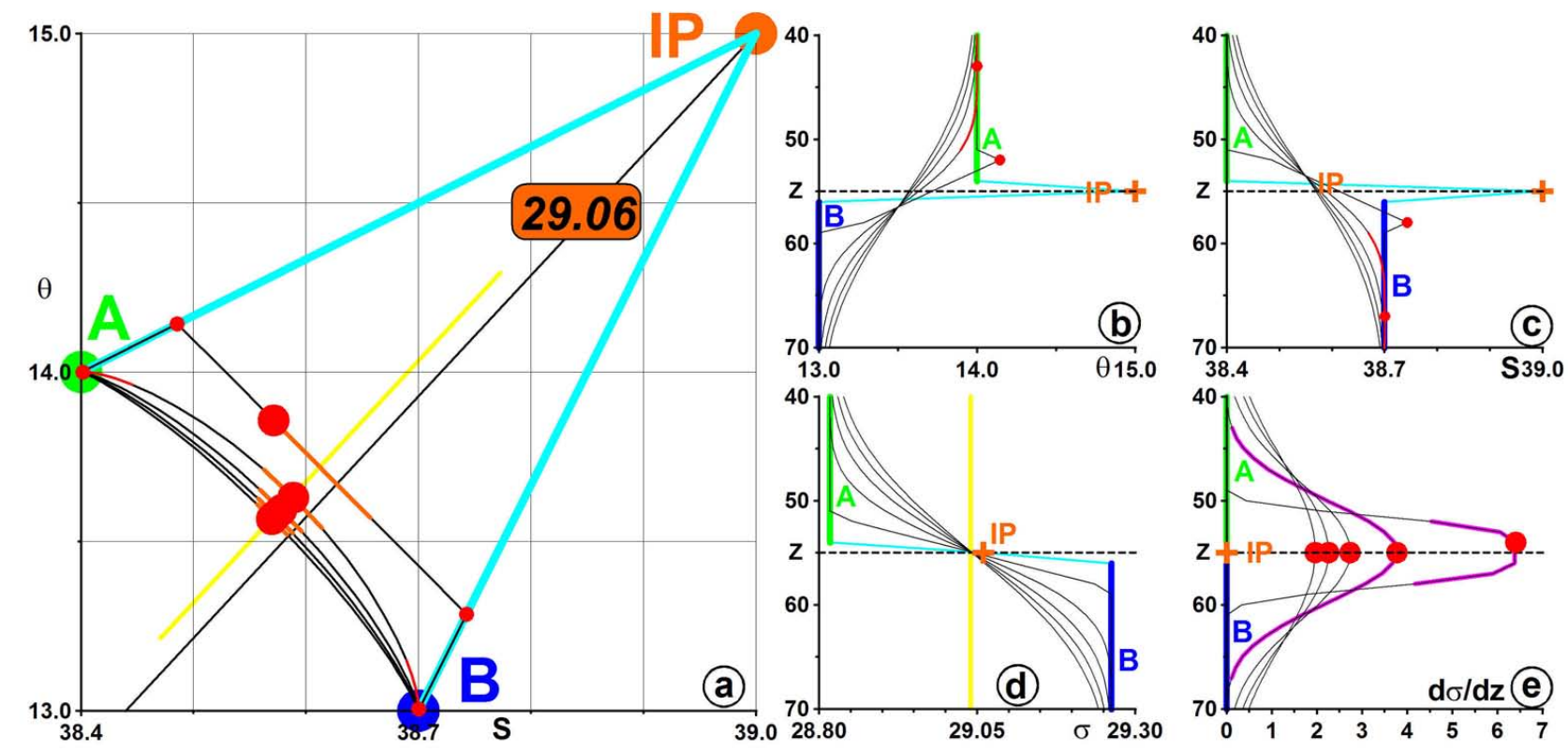

Fig. 3. - a) as in Figure 1 except for the thickness of the intermediate layer ( 9 depth units for IW, 1 for IP). Mixing reaches the IP core as soon as time step 1 (which was not the case for the IW core), creating clearly identified $\theta$ and S maxima. Such maxima then occur only at time step 2 , as indicated by the red parts of the corresponding profile and the red small dots located nearly over the A and B points. The big red dots indicating the d $\sigma / \mathrm{dz}$ maxima are rapidly associated with the $(\sigma(\mathrm{A})+\sigma(\mathrm{B})) / 2$ value. b) and c) allow the immersion of the $\theta$ and $\mathrm{S}$ maxima to be specified and emphasize their relatively rapid migration away from their initial location. $d$ ) inflection points of the $\sigma$ profiles occur at the depth of the initial IP core. e) do/dz profiles rapidly become symmetric with respect to the initial immersion of the IP core. 
values, i.e. $38 \mathrm{dbar}$ ) and then do/dz profiles (running a triangular filter with weights for $\sigma$ values of 1 at $z+1$ and $z-1$ and 0.5 at $z+2$ and $z-2$ ). Such smoothing techniques were chosen only for commodity and are expected to provide major features of the $\sigma$ and $d \sigma /$ $\mathrm{dz}$ distributions but, obviously, more sophisticated techniques should be used in a systematic analysis of a more global data set. Note that the $\theta, \mathrm{S}$ and $\mathrm{d} \sigma /$ $\mathrm{dz}$ maxima inferred from the two analyses (raw vs. smoothed data) are located at immersions that are only slightly different (generally by no more than a few 10 s m).
The GIB1 profiles (Fig. 4) display relatively similar $\theta$ maxima $\left(13.05-13.06^{\circ} \mathrm{C}\right)$ at relatively similar pressures (200-300 dbar; we deal with depths and $m$ hereafter) while the $\mathrm{S}$ maxima, although relatively similar too (38.45-38.46), occur at depths ranging from 400 to $600 \mathrm{~m}$ even if associated with similar $\theta$ values (12.96$\left.12.98^{\circ} \mathrm{C}\right)$. Overall, $\theta$ and $\mathrm{S}$ values are more similar at 200-400 m than below $400 \mathrm{~m}$, which, we think (Millot $2013 \mathrm{~b}$ ), is consistent with the relatively large southward extension of LIW in the upper levels and the marked differences in the deeper levels between the relatively warm and salty Tyrrhenian Dense Water (TDW) circu-
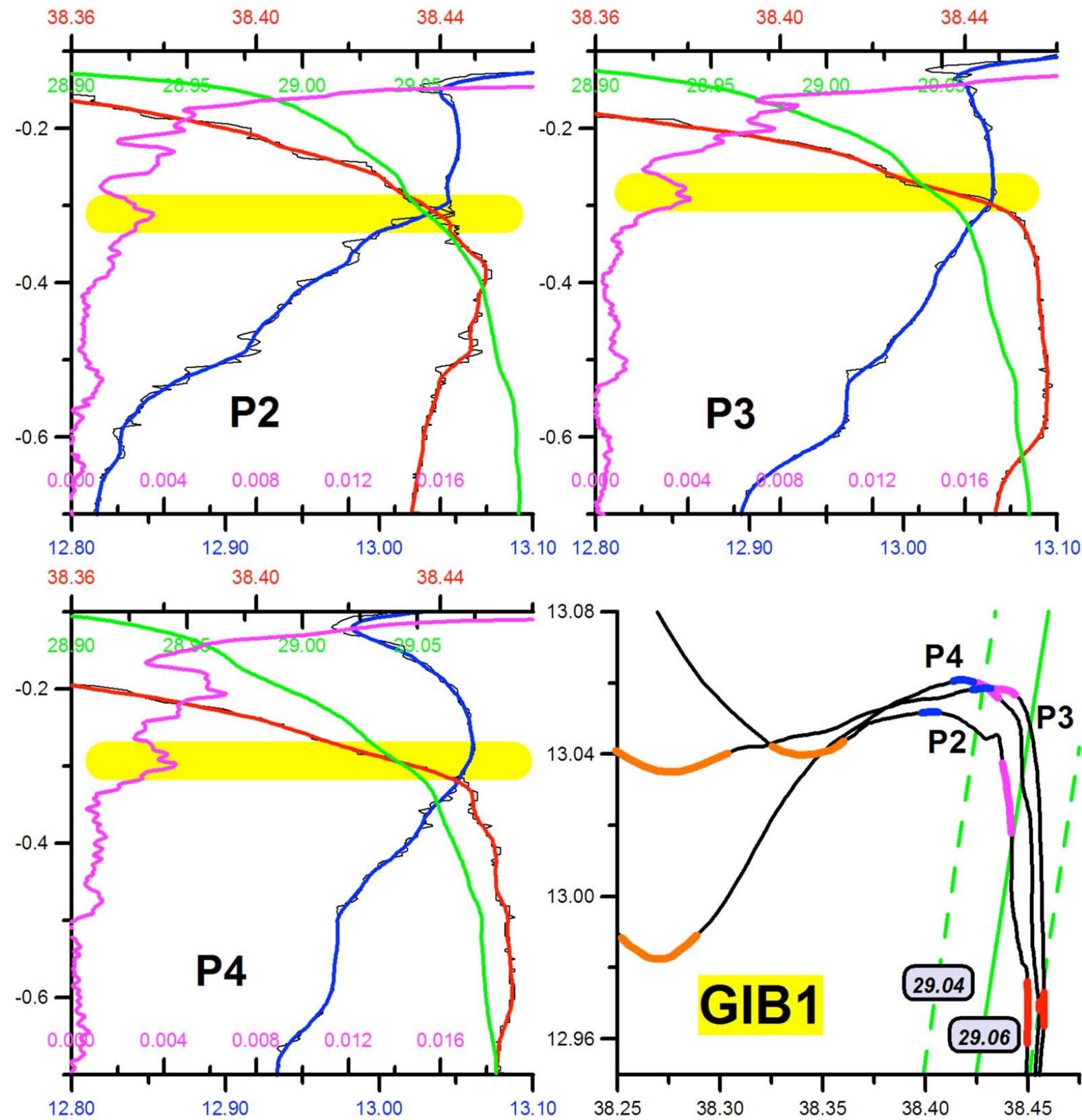

Fig. 4. - The thin black lines in the three sets of deepest and central profiles (from P2 in the south to P4 in the north) represent the raw data collected during GIB1 at $5^{\circ} 30^{\prime} \mathrm{W}$ (see Figure 3 of Millot (2013a)). Depths are in k-dbar. As specified in the text, smoothed $\theta$ (blue) and S (red) profiles allowed the $\sigma$ (green) and do/dz (pink) ones to be computed. In the $\theta$-S diagrams, the sets of the 10 extreme values for each parameter are specified in orange $(\theta$ intermediate minimum generally associated with the Western Intermediate Water), blue $(\theta$ intermediate maximum), red (S maximum) and pink (do/dz maximum, as located by the yellow bars on the profiles, which we hypothetically associate with the LIW core). 
lating along the Spanish slope in the north (P3, P4) and the relatively cool and fresh Western Mediterranean Deep Water (WMDW) uplifted along the Moroccan slope in the south (P2). Nevertheless, striking features are the similarities in the $\sigma$ profiles and variations, the latter obviously corresponding to the $\mathrm{d} \sigma / \mathrm{dz}$ similarities in the whole depths range below the AWs-MWs interface at 100-150 m; such similarities concern, in particular, the relative do/dz maxima near $300 \mathrm{~m}$ (we associate with the LIW core) and $500 \mathrm{~m}$ (possibly associated with the TDW core?). Interestingly, though it is impossible to provide any proof, defining the LIW core with the $\mathrm{d} \sigma / \mathrm{dz}$ maximum values is, at least, more accurate and objective than any inferring from the $\theta$ and $\mathrm{S}$ maxima; also, the $\mathrm{d} \sigma / \mathrm{dz}$ maxima are between the $\theta$ and $\mathrm{S}$ ones (as in the general A-B case detailed in
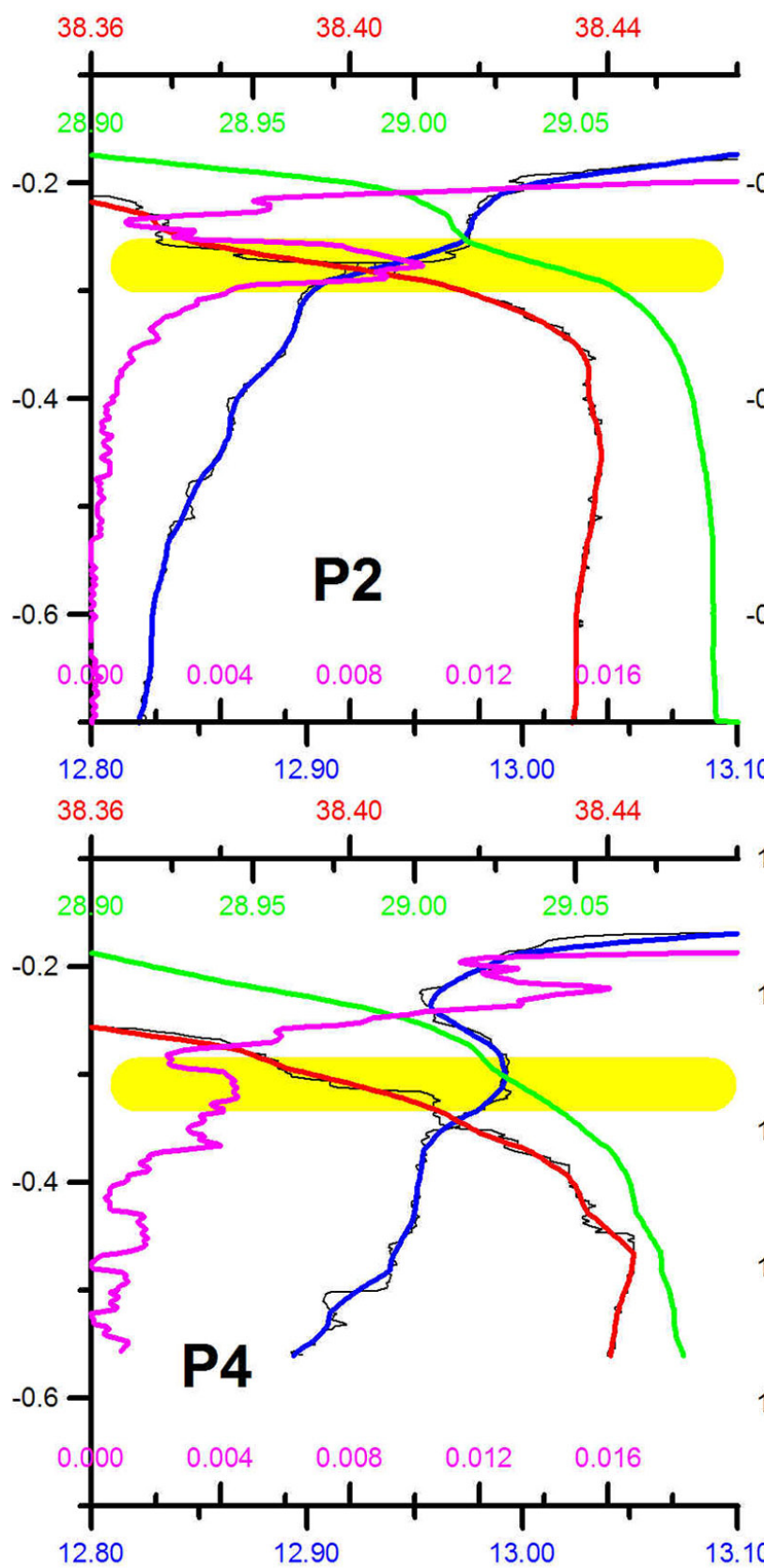

Fig. 5. - As Figure 4 for GIB2 except for the $\theta$ axis of the $\theta$-S diagrams.
Fig. 1), while being associated with relatively similar $\sigma$ values $\left(29.04-29.06 \mathrm{~kg} \mathrm{~m}^{-3}\right)$ !

As compared with GIB1, the overall situation during GIB2 (Fig. 5) is very different in the upper levels with, in particular, a much deeper AWs-MWs interface at 200-300 m. At greater depths, both the $\sigma$ and do/dz profiles display marked variations that markedly vary from P2 to P4, both at the LIW level and deeper. Even though i) no $\theta$ maximum occurs at $P 2$, ii) $\theta$ values at intermediate levels are very different, and iii) $\mathrm{S}$ maxima, still at very different depths, are associated with very different $\theta$ values, the do/dz maxima provide seemingly interesting information. When a $\theta$ maximum occurs, the $d \sigma / d z$ maximum is between the $\theta$ and $S$ ones and roughly corresponds to what one could intuitively associate with the LIW core; also note that the P2 and P4
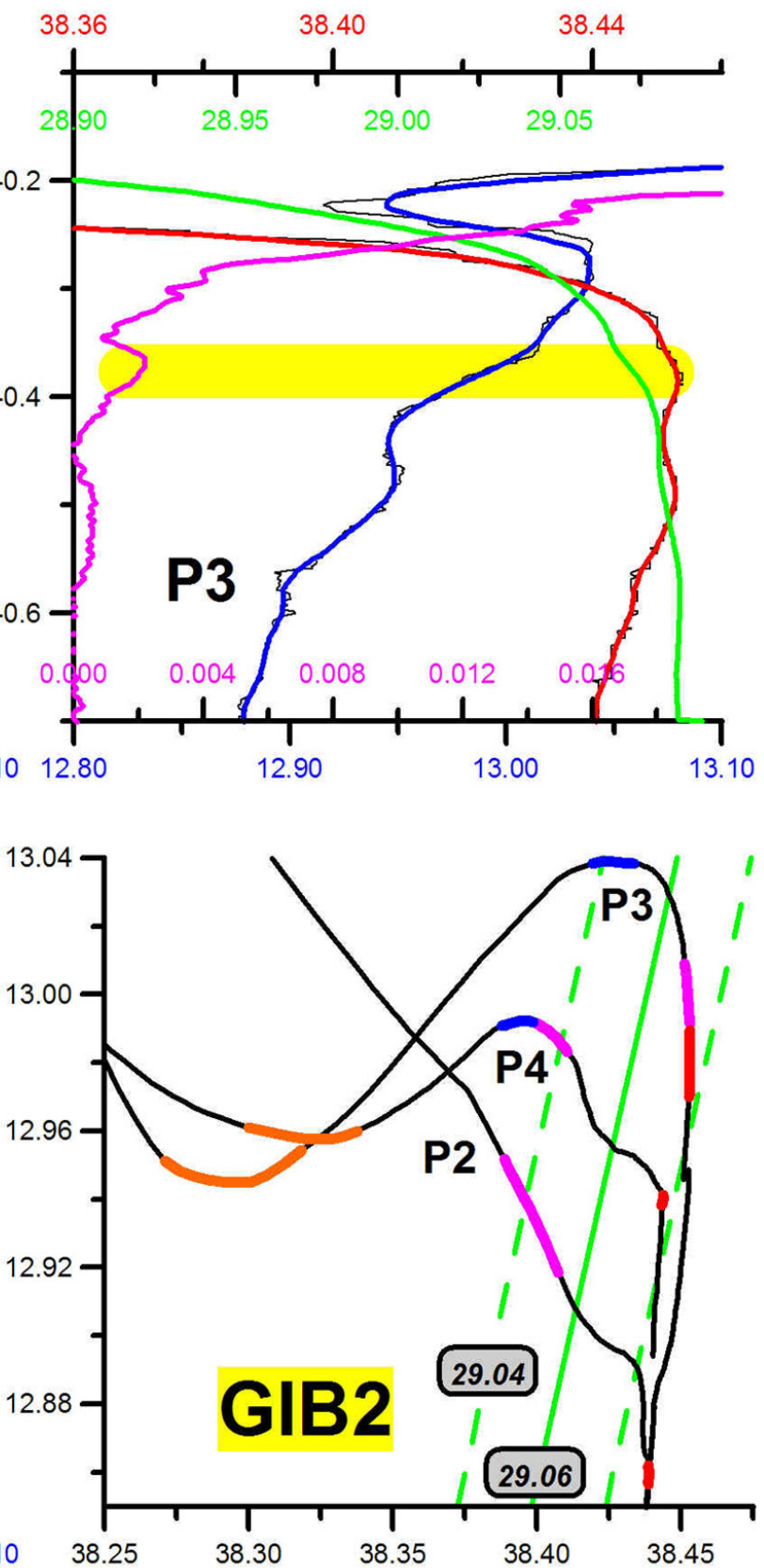
do/dz maxima at $\sim 300 \mathrm{~m}$ are associated with the same $\sigma$ value $\left(\sim 29.04 \mathrm{~kg} \mathrm{~m}^{-3}\right)$ and that if the $\mathrm{d} \sigma / \mathrm{dz}^{\mathrm{maximum}}$ at P3 corresponds to larger densities $\left(\sim 29.07 \mathrm{~kg} \mathrm{~m}^{-3}\right)$, it is found just $\sim 100 \mathrm{~m}$ below. Whatever the variability of the $\mathrm{d} \sigma / \mathrm{dz}$ distribution during GIB2, and without any a priori impossibility, one can just conclude that, as for GIB1, this parameter could provide an objective definition of the LIW core.

\section{DISCUSSION}

The title of the parent paper, "Levantine Intermediate Water characteristics: an astounding general misunderstanding" (Millot 2013a), expresses the confusion we had when we realized, just recently, that the whole community, including ourselves, did not pay enough attention and never dedicated specific theoretical studies to such a major feature of oceanic hydrology. Therefore, we just aim to illustrate our confusion and motivate dedicated theoretical studies and exhaustive data analyses.

Understanding why this IW core could be associated with a do/dz maximum should be easy when considering the simple cases analysed herein: the upper (resp. lower) part of an IW layer being mainly mixed with a less dense (resp. denser) water, the two parts obtain increasingly different $\sigma$ values, leading to a $\mathrm{d} \sigma / \mathrm{dz}$ maximum at the IW core. The IW core initially characterized by homogeneous $\theta$ and $S$ values, hence by a point or a sharp peak on a $\theta-S$ diagram and do/ $\mathrm{dz}=0$, is eroded by mixing with surrounding waters, hence leading to an increasingly smoothed peak on a $\theta$-S diagram with $\theta$ and $S$ maxima continuously moving away, which prevents them from being used as confidently as has been done up to now to characterize the IW itself. Note that the curve associated with a given profile on a $\theta-S$ diagram at depths corresponding to this IW necessarily comes to be perpendicular to the isopycnals at some specific level: this is obviously not a demonstration since no information is provided about the distribution on the vertical, but one is tempted to think that waters can mix on the vertical at this specific level less easily than at levels where the diagram is parallel to isopycnals. Another point that is also obviously not a demonstration is our feeling that sets of $\theta-S$ values collected at a regular depth interval are often more concentrated along the parts of a $\theta-S$ diagram that are nearly parallel to isopycnals than along parts that are perpendicular. This cannot be checked with the GIB1 and GIB2 data, which are relatively noisy due to both the specificity of the study area and the relative oldness of the sensors, but should offer a relatively easy opportunity to check the homogeneity vs. heterogeneity of the LIW core in the interior of the sea!

A direct consequence of this basic hypothesis, i.e. $\mathrm{d} \sigma / \mathrm{dz}$ values are relatively large at the cores of the various IWs and low along the mixing lines between two adjacents IWs, concerns the heterogeneities of the Mediterranean in- and out-flows emphasized by Millot (2013b) and synthesized by the figure reproduced
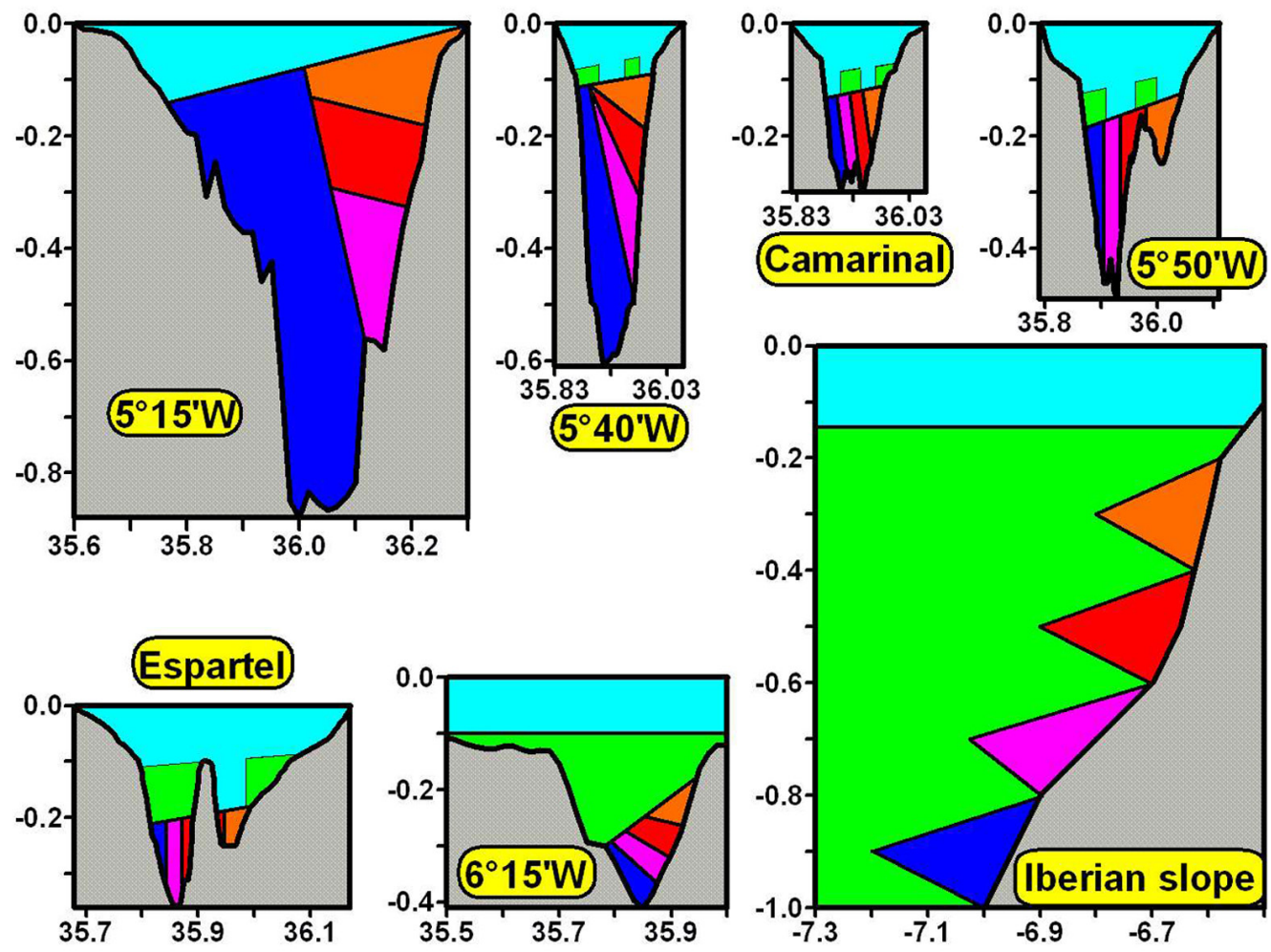

Fig. 6. - This is Figure 31 of Millot (2013b) schematizing, in the area around the Strait of Gibraltar, the distribution of SAW (Surface Atlantic Water, cyan), NACW (North Atlantic Central Water, green), WIW (Western Intermediate Water, orange), LIW (Levantine Intermediate Water, which we propose to name EIW, for Eastern Intermediate Water, red), TDW (Tyrrhenian Dense Water, pink) and WMDW (Western Mediterranean Deep Water, blue). If the hypothesis put forward in Millot (2013a) and herein were validated, apart from the blue colour that should still be associated with WMDW, the other colours should be associated more with mixtures of each of the IWs than with the IWs themselves. 
as Figure 6. The most important result leading to this schema comes from the marked differences, at the level of the MWs, between the $\theta-\mathrm{S}$ diagrams at $5^{\circ} 30^{\prime}-5^{\circ} 40^{\prime} \mathrm{W}$ (and further east) represented herein in Figures 4 and 5 , which display some overall "wavy" shape, and the diagrams at $5^{\circ} 50^{\prime}-6^{\circ} 05^{\prime} \mathrm{W}$, which display straight mixing lines between "different MWs" (as we thought) and this or that AW. This schema is based on the assumption (which we are reconsidering in Millot (2013a) and herein) that the MWs are relatively homogeneous (in $\sigma$, which is the only parameter to be considered from a dynamical point of view) and come to be so inclined within the strait (due to the increase in the outflowing speed and the Coriolis effect) that the interfaces between them reach slopes of $2 \%$ to $3 \%$, hence coming to be roughly parallel to the Moroccan continental slope and leading each of the MWs to mix independently with the AWs, giving a set of veins (up to four if all MWs are present in the outflow). If it must be considered that $\mathrm{d} \sigma / \mathrm{dz}$ values are relatively large at IWs cores and low along IWs mixing lines, then relatively homogeneous inclined layers (in the area between, roughly, $5^{\circ} 40^{\prime}$ and $5^{\circ} 50^{\prime} \mathrm{W}$ ) should correspond more to mixtures of the IWs (in particular WIW-LIW and LIW-TDW but also TDW-WMDW) than to the IWs themselves. The case of WMDW is specific since, though this MW has mixed for a while with the AWs along the Mo- roccan continental slope in the Alboran subbasin, it is uplifted and overflows in the southern part of the strait, hence leading relatively homogeneous $\theta$ and $S$ values to be associated with the WMDW core and define the densest part of the outflow, as well as the deeper vein in the ocean.

\section{ACKNOWLEDGEMENTS}

We warmly thank Michèle Fieux, who carefully read the parent paper and provided us with constructive comments, some of which led to the additional analyses herein. We also thank Gilles Reverdin, who kindly tried to find colleagues who could be interested in a discussion. We encourage anybody who would like to do so to contact us directly and we thank them in advance.

\section{REFERENCES}

Millot C. 2009. Another description of the Mediterranean Sea outflow. Progr. Oceanogr. 82(2): 101-124. http://dx.doi.org/10.1016/j.pocean.2009.04.016.

Millot C. 2013a. Levantine Intermediate Water characteristics: an astounding general misunderstanding! Sci. Mar. 77(2): 217-232. http://dx.doi.org/10.3989/scimar.03518.13A.

Millot C. 2013b. The Mediterranean Sea in- and out-flows' heterogeneities. Progr. Oceanogr. 120: 254-278. http://dx.doi.org/10.1016/j.pocean.2013.09.007. 